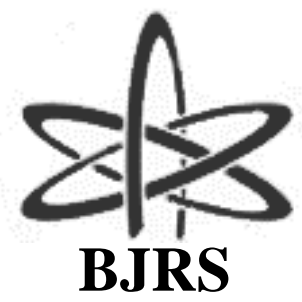

BRAZILIAN JOURNAL

$\mathrm{OF}$

RADIATION SCIENCES

07-02A (2019) 01-13

\title{
Aspects of an automatic system of implants of radioac- tive seeds and anatomic object simulator for tests in prostate brachytherapy.
}

\author{
L. S. M. Silva; V. V. B. Braga; T. P. R. Campos \\ Nuclear Engineering Department - Ionizing Radiations Nucleus /Federal University of Minas Gerais, ZIP 31270-901, \\ Belo Horizonte - MG, Brazil \\ leonardosantiago.lsms@gmail.com
}

\begin{abstract}
This work presents the development of an automatic radioactive seed implantation system (PSIS). PSIS may assist the testing permanent implants procedure in the prostate. These tests will be important in measurements of absorbed doses in the pelvic structures, involving the organs and tissues at risk to improve planning, seed positioning and dosimetry. The automated Prostate Seed Implant System (PSIS) has been designed to meet operational needs, which offers the freedom when positioning the brachytherapy needle inside the treatment area ensuring repeatability and fidelity to the planned treatment. Both the ultrasound probe and the seed implant needle are driven by stepper motors, ATMEGA microcontroller, bearings, aluminum shafts and a GUI (Graphical User Interface). Movement of both the probe and the needle holder was performed by fixed spindle on a threaded rod going through a stepper motors by a coupling. These engines were chosen due to the necessity of movements precision that these types of motors provide. The project was developed and the PSIS prototype was assembled. The prototype presented acceptable operating characteristics for prostate implants. The advantage of this system is that the automation of the application provides an accurate positioning and movement of both probe and seed application. In addition to this study, seeds implantation tests will be performed, and such tests will be essential in protocol validation processes.
\end{abstract}

Keywords: Brachytherapy, implant automatic system s, radioactive seeds.

ISSN: 2319-0612

Accepted: 2018-12-12 


\section{INTRODUCTION}

Brachytherapy in the treatment of prostate cancer has increased in recent years due to the high efficiency and relative convenience. The patient undergoes a single procedure, simple and outpatient procedure prevent hospitalization and allow a quick recover. Brachytherapy for permanent implants is performed in two steps [1]. In the first stage, the study of the prostate volume is carried out, most commonly performed by means of ultrasound images and computed tomography. The ultrasound probe is rigidly attached to a stepper device (as shown in fig. 1a) in sucha a way thatduring procedure the probe can move longitudinally over specific distances. Templates are rigidly and stably kept attached to the stepper .

After the study, the planning section is carried out by software in which the quantity, orientation and positioning of the needles are decided. The amount and activity of the seeds that will result in the desired radiation dose received by the tumor and healthy neighboring tissues are also determined. In the second stage, the seed implantation is performed as shown in Fig. 1b.

a)

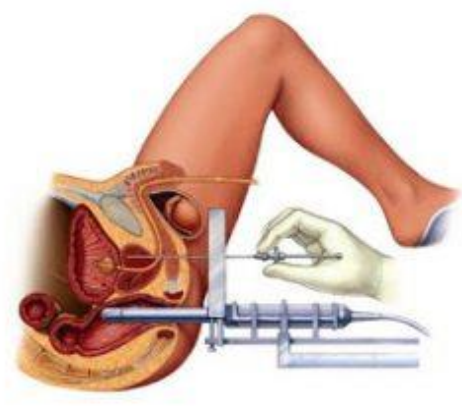

b)

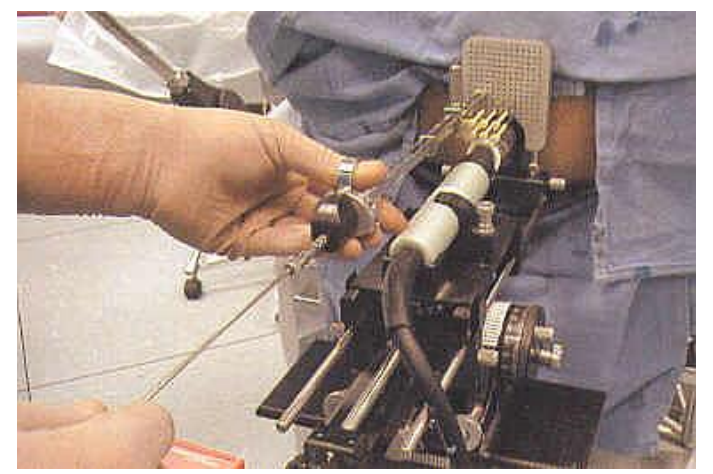

Figure 1: a) Prostate Brachytherapy - Interstitial [2]. b) Manual application of radioactive seeds [3].

In general, the patient is anesthetized to ensure their perfect immobility. The transrectal probe is introduced attempting to reproduce the positioning performed in the planning. The needles are introduced into the prostate and, as soon as the needle is extracted the seeds become deposited [1]. 
Permanent iodine-125 seed implantation presents a number of advantages over traditional methods and patients can return to normal activity, including work, within one to three days with little or no pain [4].

This work will present the design and constructive details of a new prototype using a stepper device called the Prostate Seed Implant System (PSIS). The PSIS is able to assist in the simulation of brachytherapy procedures, where implants of radioactive sources of iodine-125 and of ceramic seeds of Ho-166 will be performed in the future.

\section{MATERIALS AND METHODS}

\subsection{System design}

\subsubsection{Step motors}

The unipolar step motors have been modified to work as bipolar mode (the red wire "+Vcc" was removed), as shown in fig. 2. The torque was increased and enabled to work with the A4988 driver [5]. The main advantages of using the A4988 driver are its simplicity in controlling the bipolar step motor. A number of electrical pulses are send to the step pin, considering the number of steps required. The rotation direction ois controlled by keeping " 1 ' or " 0 " volt in the direction pin.
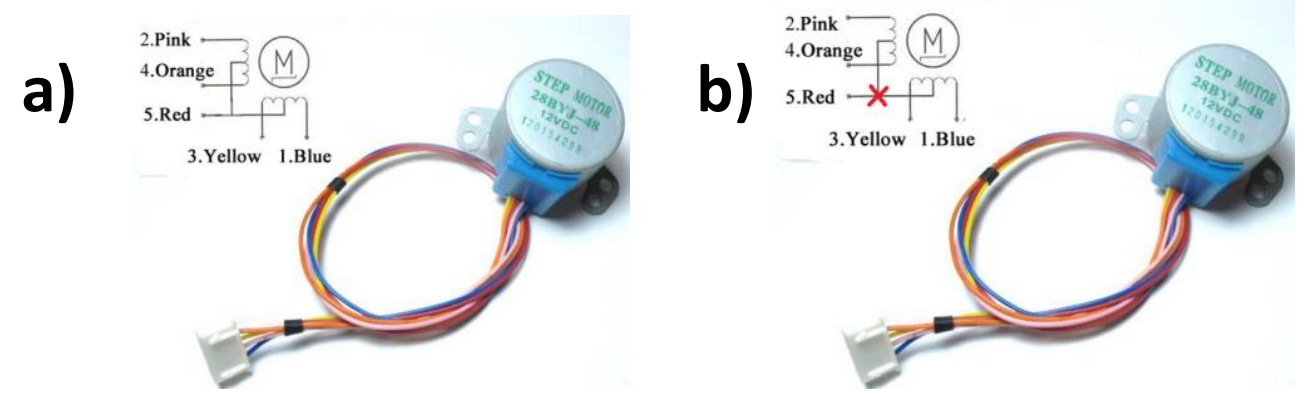

Figure 2: a) BYJ series Geared Steppper Motor 28BYJ48-12. Modified from [6] b) Modification performed on unipolar step motors to modify it in bipolar mode. Modified from [5]. 


\subsubsection{Arduino Mega 2560 - Microcontroller board}

Arduino Mega 2560 device, a free electronic prototyping platform, was adopted as part of the control of this project (Fig.3). This device has the advantages of allowing programming in $\mathrm{C} / \mathrm{C}++$ language through an Integral Development Environment (IDE) written in Java with multiple libraries that facilitates these schedules [7].

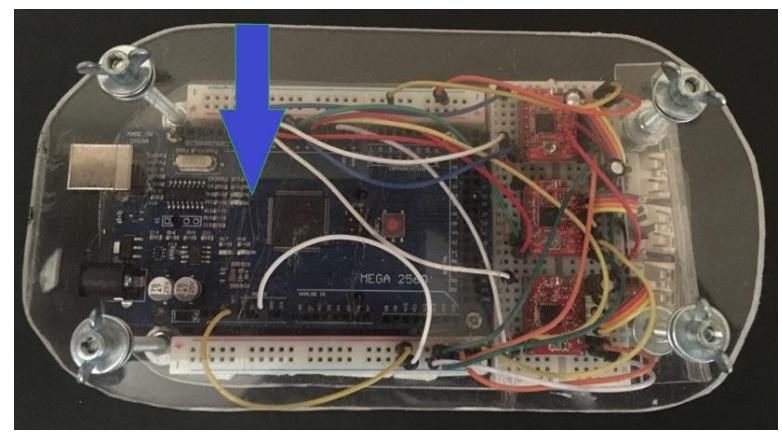

Figure 3: The Arduino Mega 2560 device.

\subsubsection{Microstepping motor driver -A4988}

A4988 is a complete microstepping motor driver with built-in translator for easy operation. It is designed to operate bipolar stepper motor with an output drive capacity of up to $35 \mathrm{~V}$ and $\pm 2 \mathrm{~A}$. A4988 includes a fixed off-time current regulator which has the ability to operate in Slow or Mixed decay modes. Inputting one pulse on the STEP input drives the motor one microstep. There are no phase sequence tables, or complex interface stop program [8]. Three A4899 were used in this project connected to the Arduino board, as shown in figure $4 \mathrm{a}$ and $4 \mathrm{~b}$. 

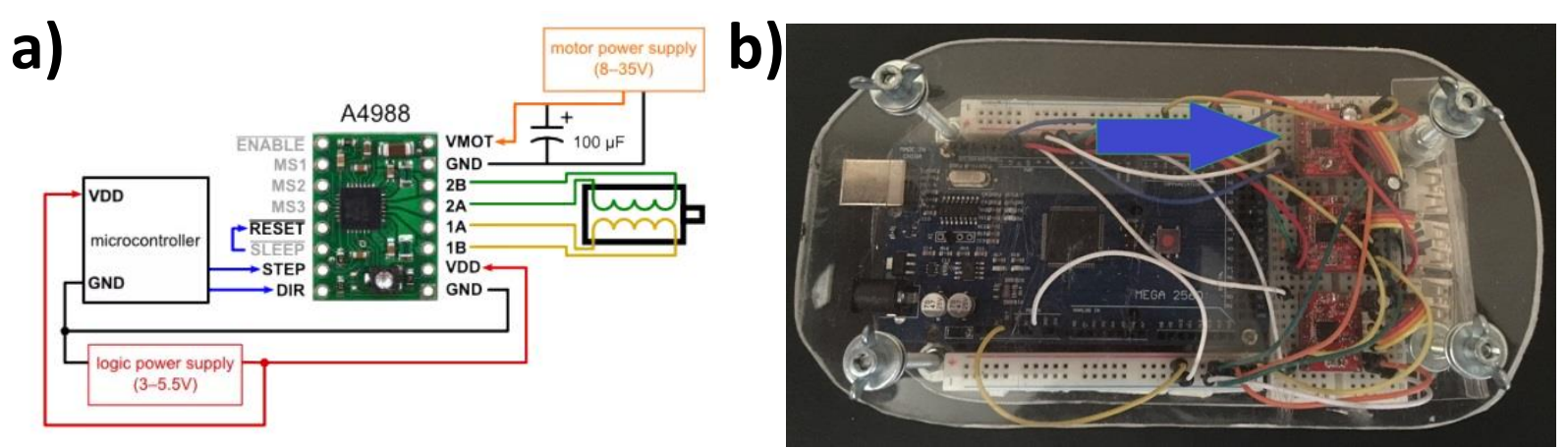

Figure 4: a) A4988 simplified diagram (Microstepping driver with translator and overcurrent protection) [8]. b) A4988 connected to Arduino board.

\subsubsection{Graphic User Interface (GUI)}

Graphical User Interface (GUI) application development can be a difficult task for scientists and engineers who do not have a strong background in programming language. High-level script based development allows scientists and engineers to focus on the specific problems they are trying to solve rather than spending enormous amounts of time architecting a GUI application using a lowlevel language.

The programming was developed using Matlab® software GUIDE (Graphical User Interface Development Environment) tool. The connection between Graphical User Interface (GUI) and Arduino board was made through universal serial bus (USB). This serial communication will be replaced by Bluetooth Communication to add a greater degree of freedom to the user.

With this interface it is possible to control the the stepper motors movement and visualize the the needle motion by webcam, as shown in fig. 5 . 


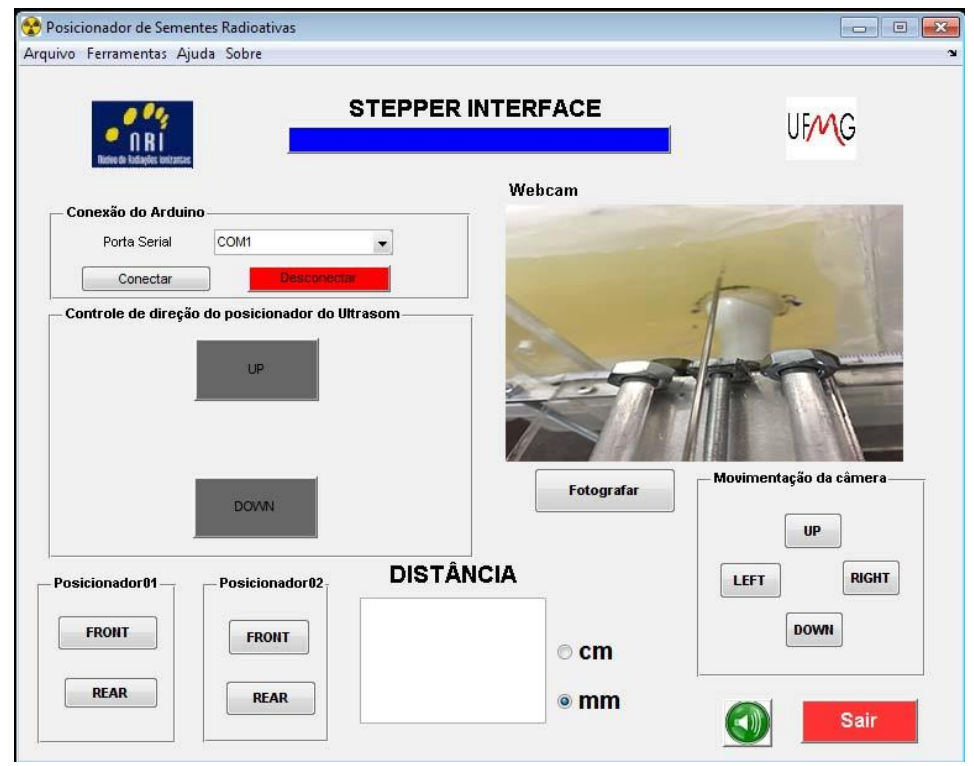

Figure 5: Graphical User Interface (GUI).

\subsubsection{Prostate Simulator}

A simulator was developed, reproducing a rectangular acrylic box measuring $18.5 \mathrm{~cm} \mathrm{x} 11.5 \mathrm{~cm} \mathrm{x}$ $9.5 \mathrm{~cm}$ filled with equivalent prostate tissue, as shown in fig.6. The prostate tissue was made with a base of collagen with salts and acids containing the elements: $\mathrm{C}, \mathrm{H}, \mathrm{O}, \mathrm{N}, \mathrm{S}, \mathrm{Na}, \mathrm{P}, \mathrm{Cl}$ and $\mathrm{K}$ [9]. The preparation of this tissue was performed in a beaker by adding the compounds of the mixture in the appropriate ratio. This mixture was heated until $60^{\circ} \mathrm{C}$. The mixture was placed in the box and brought to the refrigerator where it reached the desired consistency.

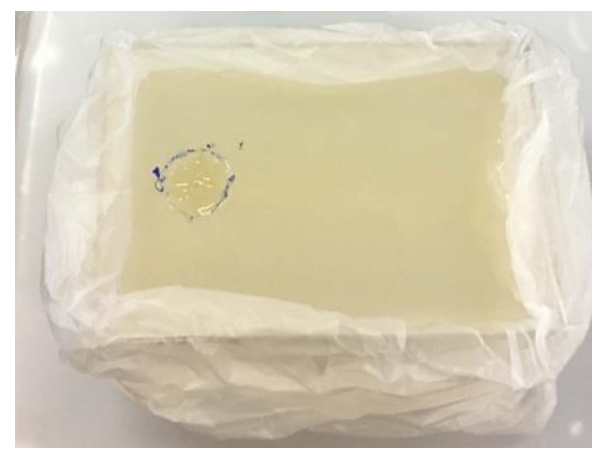

Figure 6: Prostate simulator developed to support the seeds application . 


\subsubsection{Iodine-125 seed simulators}

The treatment of prostate cancer with permanent implantation of iodine-125 seeds has grown in the world. In the international market, the minimum seed cost is US\$ 45.00 and the number of seeds required per implant is 80 to 120 units. In Brazil, the implants are made with imported seeds. The final price is very high and treatment is only carried out in private clinics and private hospitals. IPEN-CNEN/SP established a project in 2012 for the development and production of iodine-125 seeds (prototype shown in fig.7) with the purpose of minimizing costs and allowing distribution to public health entities [10].

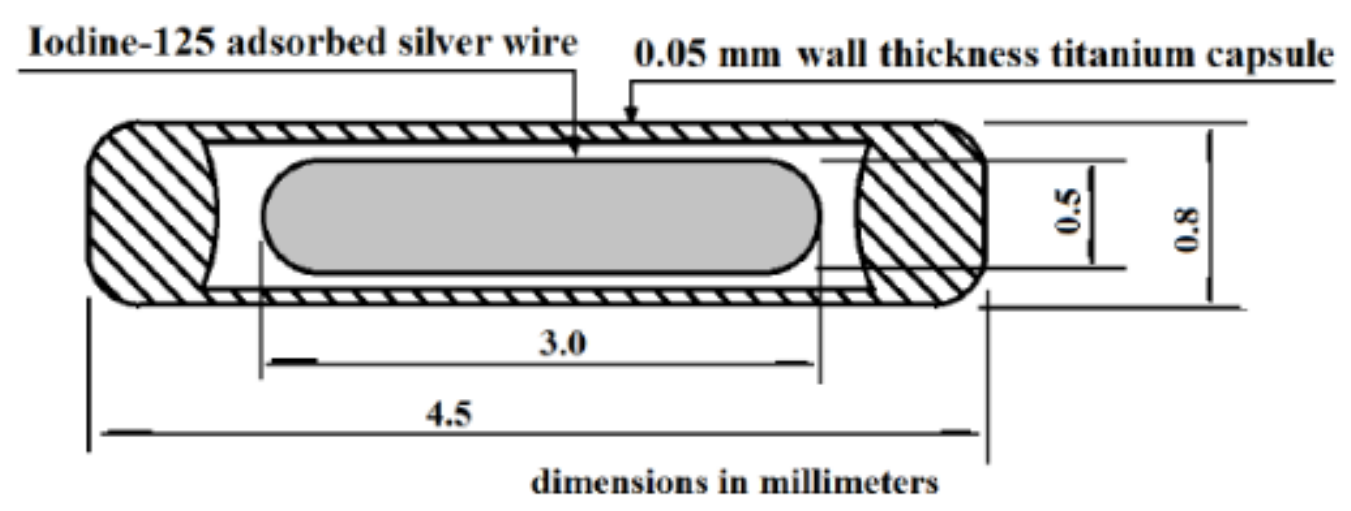

Figure 7: Schematic drawing of the iodine-125 seed [12].

Iodine-125 seeds are almost microscopic in size and smaller than a grain of rice. They are composed of a cylindrical titanium capsule of $0.8 \mathrm{~mm}$ of external diameter and $4.5 \mathrm{~mm}$ in length. Inside the capsule, a $0.5 \mathrm{~mm}$ diameter silver wire with iodine- 125 deposited on the surface is located. The activity (amount of radiation emitted by the nucleus of the isotope) typical of the seeds is $18.5 \times 10^{6}$ Bq of iodine-125 [11].

The seeds used in this project, such as dimensional iodine simulators, were small pieces of metallic and ceramic copper wires of $4.5 \mathrm{~mm}$ in length and $1 \mathrm{~mm}$ of external diameter. In this way, it maintained a similarity with the dimensions of a real iodine-125 seed. These seeds were placed in the 
following arrangement into the needle, a ceramic seed between two metallic seeds, as shown in fig. 8 .

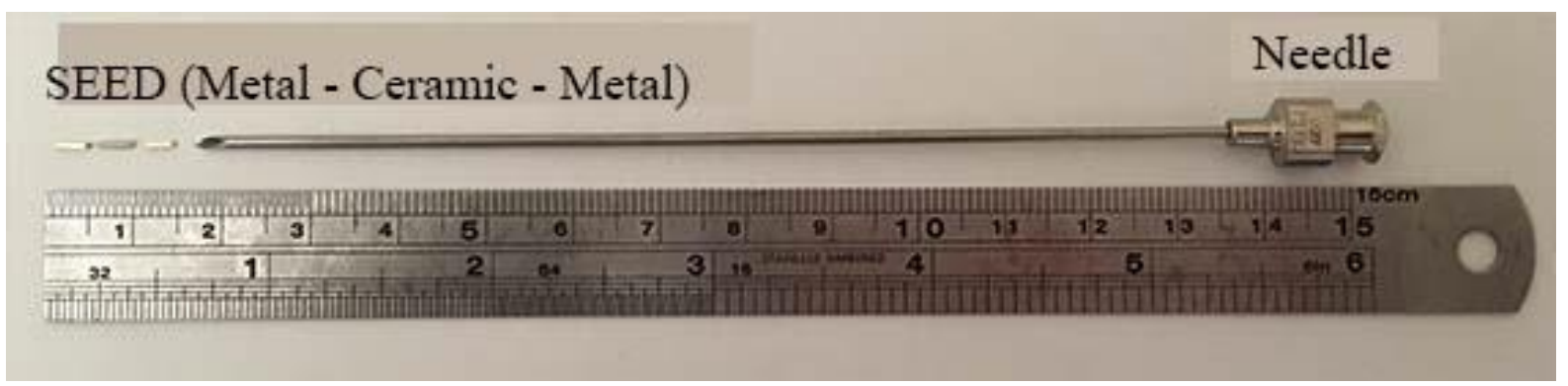

Figure 8: Prototype of iodine-125 seed used in this project.

\subsection{The application of the seeds}

After the assembly of the whole system, as shown in fig.9, three seeds were applied in the prostate simulator. As shown in the flow chart of fig. 10 .
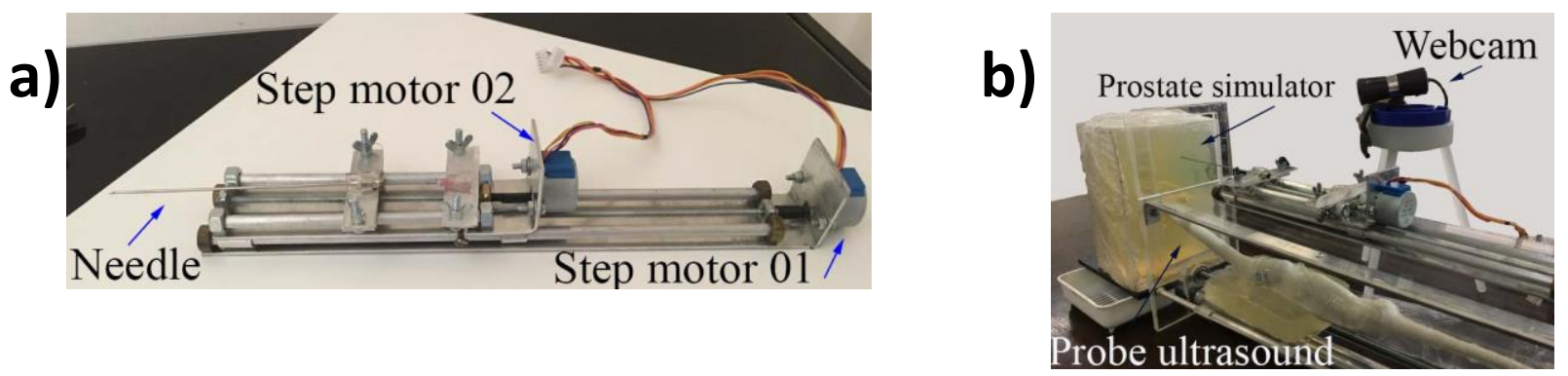

Figure 10: a) Image of the seed applicator. b) Lateral view of the PSIS system. 


\subsubsection{Flowchart}

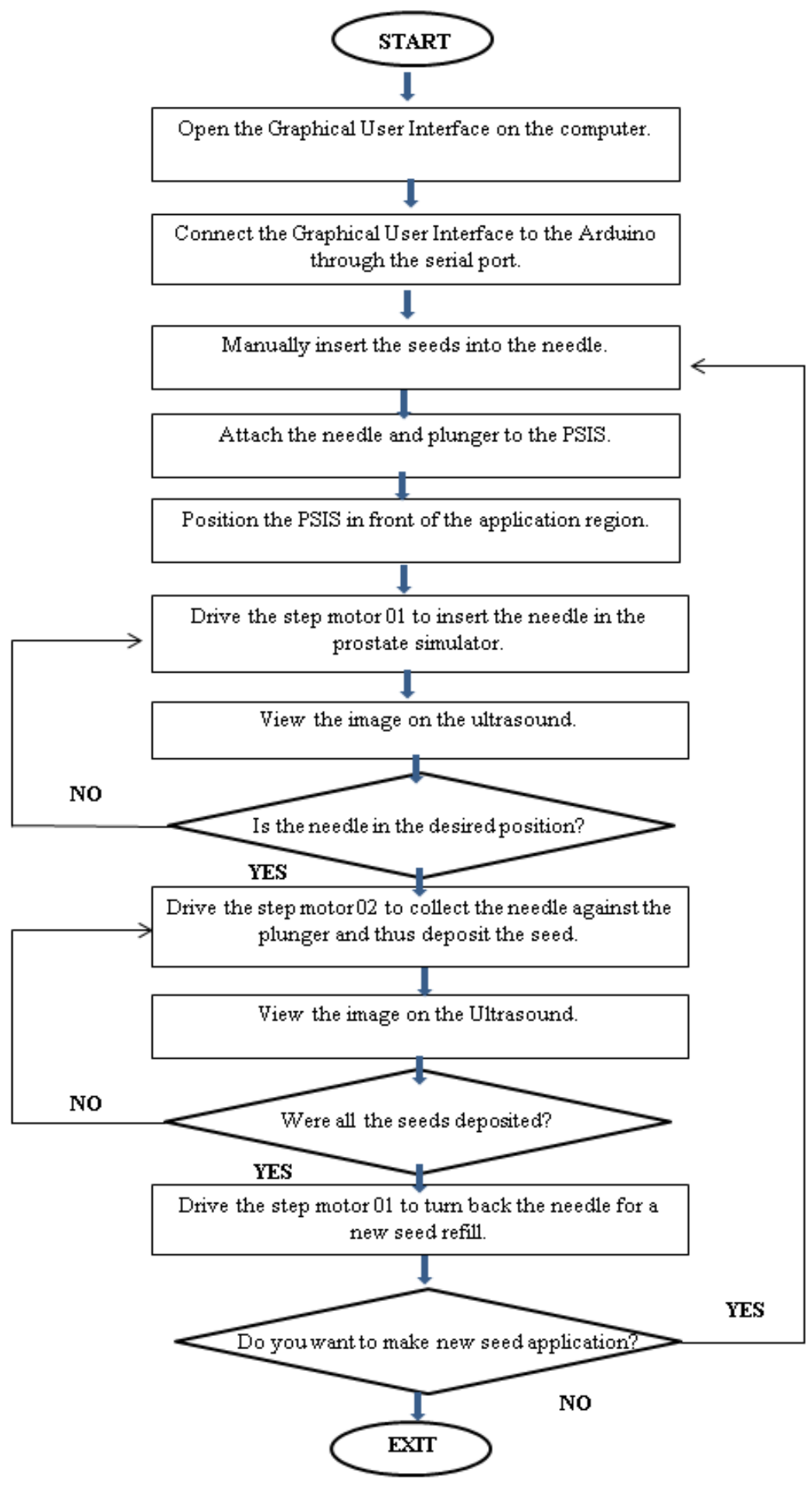

Figure 10: Flowchart of the entire system 
In fig. $11 \mathrm{a}$ is possible to visualize the needle being inserted into prostate simulator.

In fig. $11 \mathrm{~b}$ it is possible to visualize the image of the needle into prostate simulator, with the aid of the ultrasound equipment.

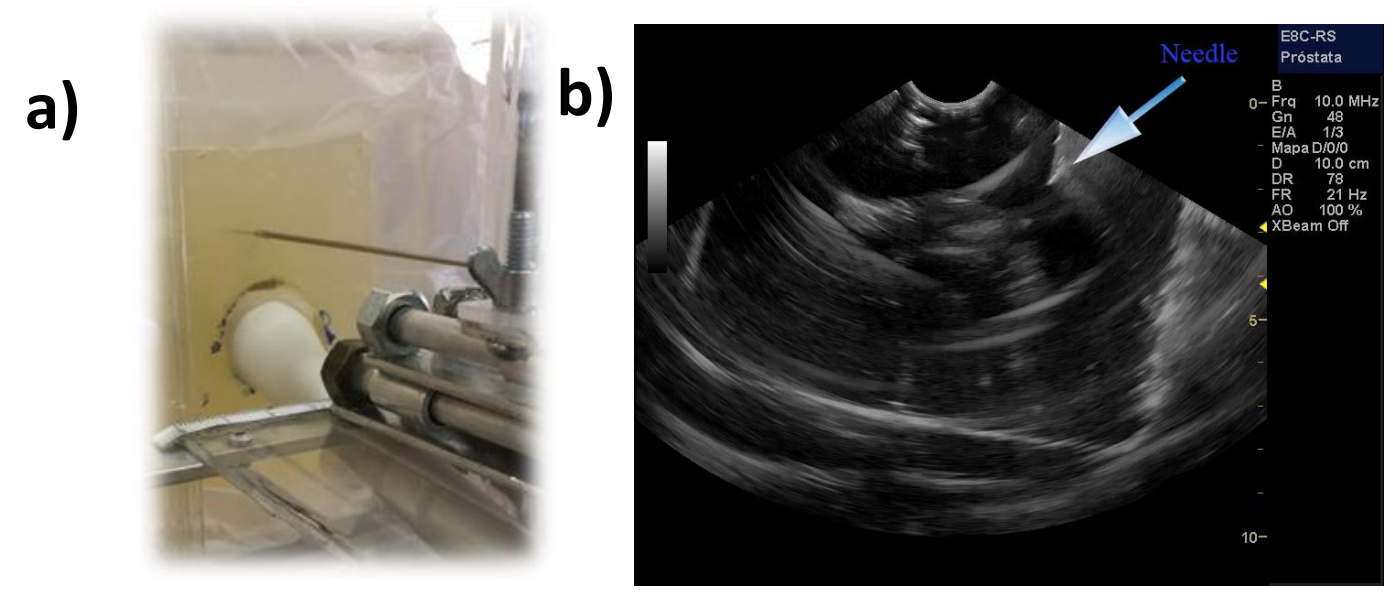

Figure 11: Image of the needle during the application procedures. a) Image observed in the prostate simulator. b) Image of needle applied and observed through ultrasound equipment.

\section{RESULTS AND DISCUSSION}

In fig. $12 \mathrm{a}$ it is possible to visualize the last metal seeds that were applied into prostate simulator. This last seed was applied very close to the surface of the prostate simulator. Therefore, allowing the visualization it directly without the aid of the ultrasound equipment.

In fig. $12 \mathrm{~b}$ it is possible to visualize all the three seeds (metal, ceramic and metal) that were applied with the system, with the aid of the ultrasound equipment. 

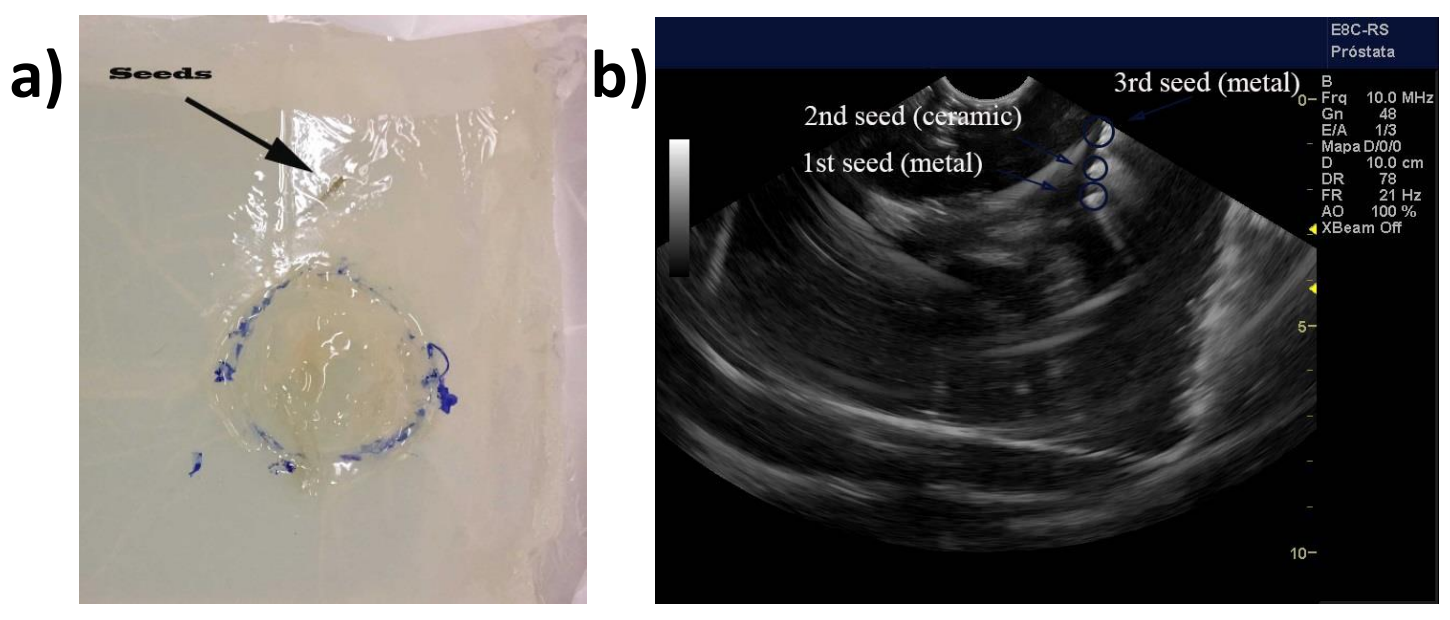

Figure 12: Image of the seeds after the application procedures. a) Image of the seeds observed in the prostate simulator. b) Image of the seeds (metal-ceramic-metal) observed through ultrasound equipment.

\section{CONCLUSION}

The system PSIS applied the seeds (metallic and ceramic) in a very satisfactory way. It shows that it is possible to automate the application of radioactive seeds of iodine-125 in prostate cancer treatments. The cost of the system is relatively low. Further studies and tests are in progress.

The future improvements in PSIS will be the design of a drive system for xy-directions movements; the design a Bluetooth communication between the Graphical User Interface (GUI) and the mechanic system; the performation of seed's implants in conjunction with assays for resolution, accuracy and precision; the creation of an implant protocol.

\section{ACKNOWLEDGMENT}

The authors thank the financial support of the National Council for Scientific and Technological Development - CNPq [456719/2013-0 REBRAT-SUS]. The design and the construction of the prototype of an automatic radioactive seed implantation system (PSIS) were performed in the Nuclear Engineering Department of the Federal University of Minas Gerais. The authors are thankful to all 
the researchers of the NRI - Núcleo de Radiações Ionizantes research group from the Department of Nuclear Engineering - UFMG who directly or indirectly contributed to the conclusion of this project.

\section{REFERENCES}

1. PEREZ C. A., Technical Basis of Radiation Therapy, Springer, p. 275, 2006.

2. MONTEIRO S. M.; DOMINGAS S. S., IVANILSON S. C., KÉLYA M. M., RAONE S. D. , WANESSA D. B. S., Tratamento Radioterápico do Câncer de Próstata. Revista Científica Multidisciplinar Núcleo do Conhecimento. Ano 2, v. 13. p. 474-481, 2017.

3. RODRIGUES R. P., Método de aplicação das fontes de iodo-125 radioncologia radioterapia, Available at:

$<$ http://ruirodrigues.net/radio2/index.php?option=com content \&view=article $\&$ id $=135 \% 3 \mathrm{~A}$ mdo-de-aplica\&catid=49\%3Abraquiterapia\&Itemid=109\&showall=1> Last accessed: 25 Jul. 2017.

4. FRANCA A. C., The seven-year preliminary results of brachytherapy with Iodine-125 seeds for localized prostate cancer treated at a Brazilian single-center. International Braz. J. Urol, v.33, n.6, Rio de Janeiro, 2007.

5. Driving 28BYJ-48 step motor with Pololu A4988/DRV8825 drivers, Available at: <http://webcache.googleusercontent.com/search?q=cache:16M90IlcnTIJ:www.electronicsm ayhem.com/\%3Fp\%3D13+\&cd=2\&hl=pt-BR\&ct=clnk\&gl=br $>$ Last accessed: 24 Jul. 2017.

6. Datasheet 28byj48, 12V, Available at:

<http://www.petervis.com/Datasheets/28byj48/28byj48.html> Last accessed: 17 Aug. 2017. 
7. TIMMIS H., Practical arduino engineering, ed. Apress Academic. EUA, 2011.

8. Datasheet DMOS microsteppingdriver with translator and overcurrent protection, Available at:

<https://www.pololu.com/file/download/a4988_DMOS_microstepping_driver_with_translat or.pdf?file_id=0J450> Last accessed: 17 Aug. 2017.

9. MATOS A. S. D., Dosimetria experimental em radioterapia de próstata com fantoma de pelve masculina, Tese de doutorado, Escola de Engenharia da Universidade Federal de Minas Gerais, Brasil, 2011.

10. ROSTELATO M. E. C. M., Estudo e desenvolvimento de uma nova metodologia para confecção de sementes de Iodo-125 para aplicação em braquiterapia, Tese de doutorado, IPEN/CNEN-SP, 2005.

11. CARLOS Z. A., Dosimetric study in iodine-125 seeds for brachytherapy application, São Paulo, 2008, Tese de doutorado, Instituto de Pesquisas Energéticas e Nucleares. Available at:

<http://www.iaea.org/inis/collection/NCLCollectionStore/_Public/46/066/46066309.pdf?r=1

> Last accessed: 12 Aug. 2017.

12. DAIANE C. B. S., MARIA E. C. R., ROBERTO V.; CARlOS A. Z.; RODRIGO T.; OSVALDO L. C.; CARLA D. S.; FERNANDO S. P. Jr.; BRUNA T. R.; ANDERSON S. S. D. K. Jr.; TALITA Q. B.; EMERSON R. M.; ANDERSON R. C., “Assessment of the risks associated with iodine-125 handling production sources for brachytherapy", International Nuclear Atlantic Conference- INAC, São Paulo, SP Brazil, v. 1, p.3, 2015.

Available at:

<https://www.researchgate.net/publication/304781417_Assessment_of_the_risks_associated _with_iodine-125_handling_production_sources_for_brachytherapy> Last accessed: 15 Aug. 2017. 